\title{
28 Research Square \\ Exploring the Clinical Characteristics of the Lymph Nodal Metastatic Regions in Patients with Endometrial Cancer
}

\section{Wonkyo Shin}

Chungnam national university

\section{Sun-Young Kim}

National Cancer Center

Sangyoon Park

National Cancer Center

Sokbom Kang

National Cancer Center

Myong Cheol Lim

National Cancer Center

Sang-Soo Seo ( $\nabla$ ssseomd@ncc.re.kr)

National cancer center https://orcid.org/0000-0003-2381-0965

\section{Research Article}

Keywords: endometrial cancer, lymph node dissection, survival

Posted Date: November 29th, 2021

DOI: https://doi.org/10.21203/rs.3.rs-944965/v1

License: (c) (1) This work is licensed under a Creative Commons Attribution 4.0 International License.

Read Full License 


\section{Abstract \\ Objective}

To evaluate clinical factors that can help determine the extent of lymphadenectomy required in endometrial cancer patients and confirm the differences of metastatic lymph node regions based on the risk factors for endometrial cancer patients.

\section{Methods}

The medical records of 468 endometrial cancer patients were retrospectively reviewed between January 2006 and December 2018. Patients were categorized into pelvic lymph node dissection (PLND) and pelvic plus para-aortic lymph nodes dissection (PPALND) groups. Demographics, recurrence-free survival, and 5year overall survival rates were compared, and the clinical factors affecting survival were evaluated using Cox proportional hazards model.

\section{Results}

The median follow-up period was 55 months (range, 6-142 months). The mean age was higher in the PPALND group than in the PLND group (51.0 vs. 54.5 years; $P<0.001)$. The PPALND group had a higher International Federation of Gynecology and Obstetrics (FIGO) stage, lymphovascular invasion, endocervical invasion, and FIGO grade $(P=0.001)$ than the PLND group. The PPALND group had higher 5year recurrence-free and overall survival rates than the PLND group. While comparing lymph node (LN) metastasis confirmed pathologically, the group with confirmed metastasis showed a higher number of high-risk group patients than lymph node-negative patients. However, no difference was observed in pelvic LN metastasis, pelvic plus para-aortic LN metastasis, and isolated para-aortic LN metastasis groups.

\section{Conclusions}

When treating patients with endometrial cancer, risk group evaluation is an important factor for determining LN dissection. Our study found no differences in clinical factors of metastatic LN regions.

\section{Introduction}

Endometrial cancer has the highest incidence among all gynecological cancers in Western countries [1], and a continuous increase in its incidence has been observed in Korea [2]. Endometrial cancer is diagnosed at a relatively early stage than other gynecological cancers, owing to patients presenting with symptoms such as vaginal bleeding or discharges, and can be easily diagnosed using endometrial biopsies, such as curettage, aspiration, or hysteroscopic biopsy. Regarding the treatment for endometrial 
cancer, surgery is performed along with the administration of adjuvant treatment based on the clinical stage. The types of surgery include total hysterectomy, bilateral salpingo-oophorectomy, and pelvic and para-aortic lymphadenectomy, and the stage is determined according to the pathology report.

The extent of lymph node $(L N)$ resection in cases of endometrial cancer has remained controversial for decades [3-7]. In 2010, the Survival Effect of Para-aortic Lymphadenectomy in Endometrial Cancer (SEPAL) study [5] reported that performing para-aortic lymph node dissection (PALND) resulted in improved survival rates among intermediate- and high-risk groups. The risk group was classified according to FIGO stage, FIGO grade, histology and lymphovascular invasion. However, limitations of this study included its retrospective nature and various biases owing to a comparison of studies conducted by different institutions that participated in the study. Only pelvic lymph node dissection (PLND) was performed in one of the institutions, and the status of the para-aortic LN was not evaluated. In contrast, several recent studies related to sentinel lymph node dissection (LND) have shown accurate detection of metastatic LNs without performing unnecessary dissections $[8,9]$.

In endometrial cancer, there is an additional issue of isolated para-aortic LN metastasis, which is known to occur in approximately $2-5 \%$ [10] of cases and is virtually impossible to identify using sentinel biopsy. Kang et al. reported that preoperative risk stratification of $L N$ metastasis in endometrioid endometrial cancer patients using preoperative serum cancer antigen 125 levels and magnetic resonance imaging could help predict LN metastasis.

The National Comprehensive Cancer Network guideline indicates that LND is necessary for accurate surgical staging; however, it does not set a range for LND. As the range for LND increases, morbidity increases, along with the operation time, and it subsequently affects the recovery rate. Therefore, it is important to determine the accurate range for LND. In addition, the indication of sentinel LND needs to be more accurate.

In this study, we analyzed the risk factors associated with LN metastasis. Exploring the clinical differences in metastatic lymph nodal regions, we aimed to evaluate clinical factors that can help determine the appropriate extent of LND required for patients with endometrial cancer.

\section{Methods}

In this study, we reviewed electronic medical records of patients newly diagnosed with endometrial cancer using endometrial biopsy and treated at the National Cancer Center in South Korea between January 2006 and December 2018. This retrospective study was approved by the Institutional Review Board of our institution (IRB No. NCC2019-0272), and the requirement of informed consent was waived owing to the retrospective nature of this study.

A total of 1,578 endometrial cancer patients visited our outpatient clinic; however, 497 of those visited only once for counseling or a second opinion, and 439 patients had recurrent disease. Therefore, 468 patients who were treated with LND were included in this study (Fig. 1). We classified the patients into 
two groups: PLND and pelvic plus para-aortic lymph nodes dissection (PPALND). In our institution, no specific risk factor was identified before surgery; there are cases where only PLND was performed or LND was omitted. The distinction between the PLND group and the PALND group was classified retrospectively as this study was conducted. The clinical characteristics of the two groups are summarized in Table 1. We first compared the clinical characteristics of patients who underwent PLND or PPALND. Additionally, we analyzed the detailed risk factors for LN involvement and investigated the appropriate range for LND. In total, 56 patients had pathologically confirmed LN metastasis (+) and were compared with those without LN metastasis (-) 
Table 1

Baseline characteristics of patients

\begin{tabular}{|c|c|c|c|c|c|c|}
\hline & & Group 1 & & Group 2 & & P-value* \\
\hline \multirow[t]{2}{*}{ Characteristic } & Value & $\begin{array}{l}(\mathrm{N}= \\
141)\end{array}$ & & $(\mathrm{N}=327)$ & & \\
\hline & & $\mathrm{N}$ & $\%$ & $\mathrm{~N}$ & $\%$ & \\
\hline Age & & 50.98 & & 54.49 & & 0.00 \\
\hline \multirow[t]{3}{*}{ Risk groups } & Low & 100 & 70.92 & 126 & 38.53 & 0.00 \\
\hline & Intermediate & 23 & 16.31 & 57 & 17.43 & \\
\hline & High & 18 & 12.77 & 144 & 44.04 & \\
\hline Tumor size $(\mathrm{cm})$ & & 2.1 & & 3.3 & & 0.00 \\
\hline $\begin{array}{l}\text { Myometrial } \\
\text { invasion }(\mathrm{mm})\end{array}$ & & 3.56 & & 7.78 & & 0.00 \\
\hline \multirow[t]{4}{*}{ Pelvic washing cytology } & Negative & 68 & 48.23 & 223 & 68.20 & 0.00 \\
\hline & Atypical cells & 20 & 14.18 & 50 & 15.29 & \\
\hline & Malignant cells & 4 & 2.84 & 14 & 4.28 & \\
\hline & Missing data & 49 & 34.75 & 40 & 12.23 & \\
\hline \multirow[t]{2}{*}{ LVSI } & Yes & 20 & 14.18 & 100 & 30.58 & 0.00 \\
\hline & No & 121 & 85.82 & 227 & 69.42 & \\
\hline \multirow[t]{2}{*}{ Histology } & Endometrioid & 130 & 92.20 & 242 & 74.01 & 0.00 \\
\hline & $\begin{array}{l}\text { Non- } \\
\text { Endometrioid }\end{array}$ & 11 & 7.80 & 85 & 25.99 & \\
\hline \multirow[t]{4}{*}{ FIGO grade } & 1 & 86 & 60.99 & 118 & 36.09 & 0.00 \\
\hline & 2 & 38 & 26.95 & 95 & 29.05 & \\
\hline & 3 & 8 & 5.67 & 54 & 16.51 & \\
\hline & Unknown & 9 & 6.38 & 60 & 18.35 & \\
\hline \multirow[t]{2}{*}{ Endocervix invasion } & Yes & 14 & 9.93 & 40 & 12.23 & 0.58 \\
\hline & No & 127 & 90.07 & 287 & 87.77 & \\
\hline \multirow[t]{2}{*}{ Cervix invasion } & Yes & 8 & 5.67 & 47 & 14.37 & 0.01 \\
\hline & No & 133 & 94.33 & 280 & 85.63 & \\
\hline FIGO stage & Stage I-II & 134 & 95.04 & 259 & 79.20 & 0.00 \\
\hline
\end{tabular}




\begin{tabular}{|lllllll|}
\hline & & Group 1 & & Group 2 & & P-value* \\
\hline & Stage III-IV & 7 & 4.96 & 68 & 20.80 & \\
\hline Adjuvant chemotherapy & Yes & 29 & 20.57 & 117 & 35.78 & 0.00 \\
& No & 112 & 79.43 & 210 & 64.22 & \\
Adjuvant radiotherapy & Yes & 23 & 16.31 & 111 & 33.94 & 0.00 \\
& No & 118 & 83.69 & 216 & 66.06 & \\
\hline
\end{tabular}

We collected data on clinical factors including age at diagnosis, International Federation of Gynecology and Obstetrics (FIGO) stage, FIGO grade, histology of the surgically removed tissues, method of surgical approach, the radicality of hysterectomy, LND, lymphovascular invasion, adjuvant chemotherapy, and radiotherapy. Risk group sub-categorization was also performed. FIGO grade 1 or 2 endometrioid cancers confined to the endometrium or with $<50 \%$ myometrial invasion was defined as low risk. Stage $1 \mathrm{~A}$ grade 3 and Stage 1B grade 1 were defined as intermediate risk. Stage IB grade 3 disease or Stages II, III, or IV disease were defined as high risk. [11] These clinical risk factors were classified using the European Society for Medical Oncology guidelines [12].

We examined the relationships of clinical factors and risk groups with PLND/PPALND groups using the chi-square test, Fisher's exact test, or Student's $t$-test. Five-year overall survival and recurrence-free survival rates were estimated using the Kaplan-Meier analysis. Patients lost to follow-up were censored. The log-rank test was used for comparing survival curves between the two groups solely and jointly with the three risk groups and FIGO stages. Cox proportional hazards model was applied to identify the predictive factors for prognosis with hazard ratios. $P$ values $<0.05$ were considered statistically significant.

\section{Results}

Data of 468 patients were selected for analysis: 141 patients received PLND alone and 327 patients received PPALND. The baseline characteristics of each group are shown in Table 1. The number of lowrisk patients was higher in the PLND group than in the PPALND group. Malignant peritoneal cytology, lymphovascular invasion, endocervical invasion, and the non-endometrioid histology ratio were higher in the PPALND group than in the PLND group; the patterns of these characteristics differed significantly between the two groups. Additionally, the FIGO stage $(P<0.001)$ was higher in the PPALND group than in the PLND group. The Kaplan-Meier survival curve showed no difference between the two groups $(p=$ 0.526 for OS, (Fig. 1), higher survival rates in the PPALND group were observed than in the PLND group in intermediate and high-risk groups ( $88.8 \%$ vs. $80.8 \%$ in the high-risk group, $94.9 \%$ vs. $89.1 \%$ in the intermediate group) (Fig. 2). These results have been reported by the SEPAL study in 2010.

The proportion of high-risk patients was higher in the LN metastasis (+) group than in the LN metastasis (-) group. Lymphovascular invasion, cervix invasion, the FIGO grade, and the FIGO stage showed 
significant differences between the LN metastasis (+) and LN metastasis (-) groups (Table 2). 
Table 2

Comparison of clinical characteristics between lymph node $(+)$ and lymph node $(-)$ metastasis patients

\begin{tabular}{|c|c|c|c|c|c|c|}
\hline & & $\begin{array}{l}\text { Group } \\
3\end{array}$ & & Others & & $\begin{array}{l}\text { P- } \\
\text { value* }\end{array}$ \\
\hline \multirow[t]{2}{*}{ Characteristic } & Value & $\begin{array}{l}(\mathrm{N}= \\
56)\end{array}$ & & $\begin{array}{l}(N= \\
412)\end{array}$ & & \\
\hline & & $\mathrm{N}$ & $\%$ & $\mathrm{~N}$ & $\%$ & \\
\hline Age & & 55.29 & & 53.18 & & 0.16 \\
\hline \multirow[t]{3}{*}{ Risk groups } & Low & 6 & 10.71 & 226 & 54.85 & 0.00 \\
\hline & Intermediate & 11 & 19.64 & 80 & 19.42 & \\
\hline & High & 39 & 69.64 & 106 & 25.73 & \\
\hline Tumor sizes(cm) & & 4.87 & & 2.65 & & 0.00 \\
\hline $\begin{array}{l}\text { Myometrial invasion } \\
\text { depth }(\mathrm{mm})\end{array}$ & & 16.41 & & 5.16 & & 0.00 \\
\hline \multirow[t]{4}{*}{ Pelvic washing cytology } & Negative & 37 & 66.07 & 254 & 61.65 & 0.02 \\
\hline & Atypical cells & 7 & 12.50 & 63 & 15.29 & \\
\hline & Malignant cells & 6 & 10.71 & 12 & 2.91 & \\
\hline & Missing data & 6 & 10.71 & 83 & 20.15 & \\
\hline \multirow[t]{2}{*}{ LVSI } & Yes & 39 & 69.64 & 81 & 19.66 & 0.00 \\
\hline & No & 17 & 30.36 & 331 & 80.34 & \\
\hline \multirow[t]{2}{*}{ Histology } & Endometrioid & 29 & 51.79 & 343 & 83.25 & 0.00 \\
\hline & $\begin{array}{l}\text { Non- } \\
\text { Endometrioid }\end{array}$ & 27 & 48.21 & 69 & 16.75 & \\
\hline \multirow[t]{4}{*}{ FIGO grade } & 1 & 5 & 8.93 & 199 & 48.30 & 0.00 \\
\hline & 2 & 15 & 26.79 & 118 & 28.64 & \\
\hline & 3 & 15 & 26.79 & 47 & 11.41 & \\
\hline & unknown & 21 & 37.50 & 48 & 11.65 & \\
\hline \multirow[t]{2}{*}{ Endocervix invasion } & Yes & 10 & 17.86 & 44 & 10.68 & 0.18 \\
\hline & No & 46 & 82.14 & 368 & 89.32 & \\
\hline \multirow[t]{2}{*}{ Cervix invasion } & Yes & 24 & 42.86 & 31 & 7.52 & 0.00 \\
\hline & No & 32 & 57.14 & 381 & 92.48 & \\
\hline
\end{tabular}

* Fisher' exact test for Pervic washing cytology, and X-square test for all the other variables 


\begin{tabular}{|lllllll|}
\hline & & $\begin{array}{l}\text { Group } \\
\mathbf{3}\end{array}$ & & Others & $\begin{array}{c}\text { P- } \\
\text { value* }\end{array}$ \\
\hline FIGO stage & I/II & 0 & 0.00 & 393 & 95.39 & 0.00 \\
\hline & III/IV & 56 & 100.00 & 19 & 4.61 & \\
\hline Adjuvant chemotherapy & Yes & 47 & 83.93 & 99 & 24.03 & 0.00 \\
\hline Adjuvant radiotherapy & No & 9 & 16.07 & 313 & 75.97 & \\
\hline & Yes & 40 & 71.43 & 94 & 22.82 & 0.00 \\
\hline * Fisher' exact test for Pervic washing cytology, and X-square test for all the other variables & \\
\hline
\end{tabular}

We subcategorized patients in the LN metastasis (+) group into three distinct sub-groups: pelvic metastasis, para-aortic metastasis, and pelvic and para-aortic metastasis. Their clinical characteristics are summarized in Table 3. Clinical factors were not significantly different among the sub-groups. Kaplan-Meier analysis of recurrence-free survival and overall survival curves is shown in Fig. 3. Recurrence-free survival was significantly different between the groups, whereas overall survival was not significantly different. Myometrial invasion depth was the only clinical factor associated with recurrencefree and overall survival (Table 3). 
Table 3

Comparison of clinical characteristics among statuses of lymph node metastasis

\begin{tabular}{|c|c|c|c|c|c|c|c|c|}
\hline \multirow{3}{*}{ Characteristic } & \multirow{3}{*}{ Value } & \multirow{2}{*}{\multicolumn{2}{|c|}{$\begin{array}{l}\text { Pelvic LN } \\
\text { metastasis } \\
(\mathrm{N}=19)\end{array}$}} & \multirow{2}{*}{\multicolumn{2}{|c|}{$\begin{array}{l}\text { Para-aortic LN } \\
\text { metastasis } \\
(\mathrm{N}=29)\end{array}$}} & \multirow{2}{*}{\multicolumn{2}{|c|}{$\begin{array}{l}\text { Pelvic \& para- } \\
\text { aortic LN } \\
\text { metastasis } \\
(\mathrm{N}=8)\end{array}$}} & \multirow[t]{3}{*}{$\begin{array}{l}\mathrm{P}- \\
\text { value }\end{array}$} \\
\hline & & & & & & & & \\
\hline & & $N$ & $\%$ & $\mathrm{~N}$ & $\%$ & $\mathrm{~N}$ & $\%$ & \\
\hline \multicolumn{2}{|c|}{ Age } & \multicolumn{2}{|c|}{51.63} & \multicolumn{2}{|c|}{57.17} & \multicolumn{2}{|l|}{57.12} & $0.16^{\$}$ \\
\hline \multirow[t]{3}{*}{ Risk groups } & Low & 2 & 10.53 & 4 & 13.79 & 0 & 0 & $0.18^{*}$ \\
\hline & Intermediate & 7 & 36.84 & 3 & 10.34 & 1 & 12.5 & \\
\hline & High & 10 & 52.63 & 22 & 75.86 & 7 & 87.5 & \\
\hline \multicolumn{2}{|l|}{ Tumor size } & \multicolumn{2}{|l|}{4.29} & \multicolumn{2}{|l|}{4.82} & \multicolumn{2}{|l|}{6.40} & $0.37^{\$}$ \\
\hline \multicolumn{2}{|l|}{$\begin{array}{l}\text { Myometrial } \\
\text { invasion }\end{array}$} & \multicolumn{2}{|c|}{14.08} & \multicolumn{2}{|c|}{17.09} & \multicolumn{2}{|l|}{23.00} & $0.43^{\$}$ \\
\hline \multirow{4}{*}{$\begin{array}{l}\text { Pelvic } \\
\text { washing } \\
\text { cytology }\end{array}$} & Negative & 11 & 57.89 & 19 & 65.52 & 7 & 87.5 & $0.68 *$ \\
\hline & Atypical cells & 2 & 10.53 & 4 & 13.79 & 1 & 12.5 & \\
\hline & $\begin{array}{l}\text { Malignant } \\
\text { cells }\end{array}$ & 2 & 10.53 & 4 & 13.79 & 0 & 0 & \\
\hline & Missing data & 4 & 21.05 & 2 & 6.90 & 0 & 0 & \\
\hline \multirow[t]{2}{*}{ LVSI } & Yes & 10 & 52.63 & 24 & 82.76 & 5 & 62.5 & $0.07 *$ \\
\hline & No & 9 & 47.37 & 5 & 17.24 & 3 & 37.5 & \\
\hline \multirow[t]{2}{*}{ Histology } & Endometrioid & 12 & 63.16 & 13 & 44.83 & 4 & 50 & $0.47^{\star}$ \\
\hline & $\begin{array}{l}\text { Non- } \\
\text { Endometrioid }\end{array}$ & 7 & 36.84 & 16 & 55.17 & 4 & 50 & \\
\hline \multirow[t]{4}{*}{ FIGO grade } & 1 & 4 & 21.05 & 1 & 3.45 & 0 & 0 & $0.45^{\star}$ \\
\hline & 2 & 6 & 31.58 & 7 & 24.14 & 2 & 25 & \\
\hline & 3 & 3 & 15.79 & 9 & 31.03 & 3 & 37.5 & \\
\hline & unknown & 6 & 31.58 & 12 & 41.38 & 3 & 37.5 & \\
\hline \multirow{2}{*}{$\begin{array}{l}\text { Endocervix } \\
\text { invasion }\end{array}$} & Yes & 3 & 15.79 & 6 & 20.69 & 1 & 12.5 & $1.00 *$ \\
\hline & No & 16 & 84.21 & 23 & 79.31 & 7 & 87.5 & \\
\hline \multicolumn{9}{|c|}{ * Fisher' exact test } \\
\hline$\$$ ANOVA test & & & & & & & & \\
\hline
\end{tabular}




\begin{tabular}{|c|c|c|c|c|c|c|c|c|}
\hline \multirow{3}{*}{$\begin{array}{l}\text { Characteristic } \\
\text { Cervix } \\
\text { invasion }\end{array}$} & \multirow{3}{*}{$\begin{array}{l}\text { Value } \\
\text { Yes }\end{array}$} & \multirow{2}{*}{\multicolumn{2}{|c|}{$\begin{array}{l}\text { Pelvic } L N \\
\text { metastasis } \\
(\mathrm{N}=19)\end{array}$}} & \multirow{2}{*}{\multicolumn{2}{|c|}{$\begin{array}{l}\text { Para-aortic LN } \\
\text { metastasis } \\
(\mathrm{N}=29)\end{array}$}} & \multirow{2}{*}{\multicolumn{2}{|c|}{$\begin{array}{l}\text { Pelvic \& para- } \\
\text { aortic LN } \\
\text { metastasis } \\
(\mathrm{N}=8)\end{array}$}} & \multirow{3}{*}{$\begin{array}{l}\begin{array}{l}\text { P- } \\
\text { value }\end{array} \\
0.10 *\end{array}$} \\
\hline & & & & & & & & \\
\hline & & 11 & 57.89 & 12 & 41.38 & 1 & 12.5 & \\
\hline & No & 8 & 42.11 & 17 & 58.62 & 7 & 87.5 & \\
\hline FIGO stage & III/IV & 19 & 100.00 & 29 & 100.00 & 8 & 100.00 & \\
\hline \multicolumn{9}{|c|}{ * Fisher' exact test } \\
\hline \multicolumn{2}{|l|}{$\$$ ANOVA test } & & & & & & & \\
\hline
\end{tabular}

\section{Discussion}

To the best of our knowledge, this is the first study to compare clinical factors by sub-dividing the site of LN metastasis. Our findings indicate that clinical differences among the metastatic position of pelvic and para-aortic LNs are non-significant, emphasizing the need for considering LN metastasis as an independent risk factor.

Regarding early endometrial cancer cases confined to the uterus, determining the range for LND remains challenging. In our study, we observed that though patients undergoing PPALND had a better survival rate than those undergoing PLND, it was known that survival was also good even when LND was not performed in the early-stage endometrial cancer $[6,13,14]$.

Contrarily, LN metastasis (+) patients were mostly in Stage III, and the ratio of risk factors was clearly different from that of LN metastasis (-) patients with respect to LVSI, non-endometrioid histology, high FIGO grade, cervix invasion, deeper myometrial invasion, and large tumor size. In the presence of a risk factor, it appeared necessary to perform a full dissection for accurate staging.

In the case of endometrial cancer surgery, the extent of performing LND has been a long-standing debate. The SEPAL study concluded that a complete PALND resulted in improved survival in high-risk group patients; however, its effect in low-to-intermediate-risk patients remains unclear. Reducing unnecessary procedures, including LND, plays a very important role in improving the patients' quality of life following treatment and preventing various complications intraoperatively.

The results of this study support expanding the range for LND in the presence of a risk factor; however, when patients were confirmed as having LN metastasis, no significant difference was observed in the risk factors. In addition, no difference in risk group assessment was observed, which is used as a reference for determining the surgical scope. To the best of our knowledge, this study is the first to analyze the risk factors while considering the status of LN metastasis. The SEPAL study only compared the rate of 
survival among the ranges for LND performed. However, in our study, we compared the locations of metastatic $L N(s)$ and found no significant difference among them.

Recently, sentinel LND is often being implemented in low-risk groups. Sentinel LND, which has been widely practiced recently, performs sampling by investigating the first LN drained from the uterus to avoid full dissection. However, the exact mechanism of lymphatic drainage remains unknown in gynecological cancers [15-18].

Anxiety regarding isolated para-aortic LN metastasis has been persistent. In general, its occurrence is 2$5 \%$; however, when LN metastasis was categorized into three groups in our study, the cases of isolated para-aortic LN metastasis did not show any remarkable risk factors.

In conclusion, in the absence of a risk factor, no LND is required, and in the presence of a risk factor, complete LND is required to eliminate issues regarding isolated para-aortic LN metastasis.

Implementation of LND by classifying it as no LND at an early stage without risk factor(s) and as full LND at an early stage with risk factor(s) appears more beneficial than expanding the range for LND gradually from no LND to PLND and subsequently from PLND to PPALND, depending on the risk.

\section{Declarations}

\section{Conflict of Interest Statement}

The authors declare no competing interests.

\section{Funding}

This research was funded by National Cancer Center (NCC), South Korea (grant no. NCC-1910180)

\section{Authors' Contributions}

Conceptualization: Wonkyo Shin, Sang-soo Seo

Data analysis: Wonkyo Shin, Sun-Young Kim

Manuscript draft: Wonkyo Shin, Sun-Young Kim

Manuscript revision and review: Myongcheol Lim, Sang-yoon Park, Sokbom Kang

Supervision: Sang-soo Seo

\section{References}

1. Siegel RL, Miller KD, Jemal A. Cancer Statistics, 2017. CA Cancer J Clin 2017;67:7-30. 
2. Lim MC, Won YJ, Ko MJ, Kim M, Shim SH, Suh DH, et al. Incidence of cervical, endometrial, and ovarian cancer in Korea during 1999-2015. J Gynecol Oncol 2019;30:e38.

3. Benedetti Panici P, Basile S, Maneschi F, Alberto Lissoni A, Signorelli M, Scambia G, et al. Systematic pelvic lymphadenectomy vs. no lymphadenectomy in early-stage endometrial carcinoma: randomized clinical trial. J Natl Cancer Inst 2008;100:1707-16.

4. Kitchener H, Swart AM, Qian Q, Amos C, Parmar MK. Efficacy of systematic pelvic lymphadenectomy in endometrial cancer (MRC ASTEC trial): a randomised study. Lancet 2009;373:125-36.

5. Todo Y, Kato H, Kaneuchi M, Watari H, Takeda M, Sakuragi N. Survival effect of para-aortic lymphadenectomy in endometrial cancer (SEPAL study): a retrospective cohort analysis. Lancet 2010;375:1165-72.

6. Kumar S, Podratz KC, Bakkum-Gamez JN, Dowdy SC, Weaver AL, McGree ME, et al. Prospective assessment of the prevalence of pelvic, paraaortic and high paraaortic lymph node metastasis in endometrial cancer. Gynecol Oncol 2014;132:38-43.

7. Papathemelis T, Oppermann H, Grafl S, Gerken M, Pauer A, Scharl S, et al. Long-term outcome of patients with intermediate- and high-risk endometrial cancer after pelvic and paraaortic lymph node dissection: a comparison of laparoscopic vs. open procedure. J Cancer Res Clin Oncol 2020;146:9619.

8. Bogani G, Murgia F, Ditto A, Raspagliesi F. Sentinel node mapping vs. lymphadenectomy in endometrial cancer: A systematic review and meta-analysis. Gynecol Oncol 2019;153:676-83.

9. Wang T, Hu Y, He Y, Sun P, Guo Z. A retrospective validation study of sentinel lymph node mapping for high-risk endometrial cancer. Arch Gynecol Obstet 2019;299:1429-35.

10. Abu-Rustum NR, Gomez JD, Alektiar KM, Soslow RA, Hensley ML, Leitao MM, Jr., et al. The incidence of isolated paraaortic nodal metastasis in surgically staged endometrial cancer patients with negative pelvic lymph nodes. Gynecol Oncol 2009;115:236-8.

11. Scott SA, van der Zanden C, Cai E, McGahan CE, Kwon JS. Prognostic significance of peritoneal cytology in low-intermediate risk endometrial cancer. Gynecol Oncol 2017;145:262-8.

12. Colombo N, Creutzberg C, Amant F, Bosse T, González-Martín A, Ledermann J, et al. ESMO-ESGOESTRO Consensus Conference on Endometrial Cancer: diagnosis, treatment and follow-up.

13. Ignatov A, Ivros S, Bozukova M, Papathemelis T, Ortmann O, Eggemann H. Systematic lymphadenectomy in early stage endometrial cancer. Arch Gynecol Obstet 2020;302:231-9.

14. Nayyar N, Lakhwani P, Goel A, Pande PK, Kumar K. The Futility of Systematic Lymphadenectomy in Early-Stage Low-grade Endometrial Cancer. Indian J Surg Oncol 2018;9:204-10.

15. Paño B, Sebastià C Fau - Ripoll E, Ripoll E Fau - Paredes P, Paredes P Fau - Salvador R, Salvador R Fau - Buñesch L, Buñesch L Fau - Nicolau C, et al. Pathways of lymphatic spread in gynecologic malignancies. 2015.

16. Geppert B, Lonnerfors C, Bollino M, Arechvo A, Persson J. A study on uterine lymphatic anatomy for standardization of pelvic sentinel lymph node detection in endometrial cancer. Gynecol Oncol 2017;145:256-61.

Page 13/15 
17. Abdelazim IA, Abu-Faza M, Zhurabekova G, Shikanova S, Karimova B, Sarsembayev M, et al. Sentinel Lymph Nodes in Endometrial Cancer Update 2018. Gynecol Minim Invasive Ther 2019;8:94-100.

18. Holloway RW, Abu-Rustum NR, Backes FJ, Boggess JF, Gotlieb WH, Jeffrey Lowery W, et al. Sentinel lymph node mapping and staging in endometrial cancer: A Society of Gynecologic Oncology literature review with consensus recommendations. Gynecol Oncol 2017;146:405-15.

\section{Figures}
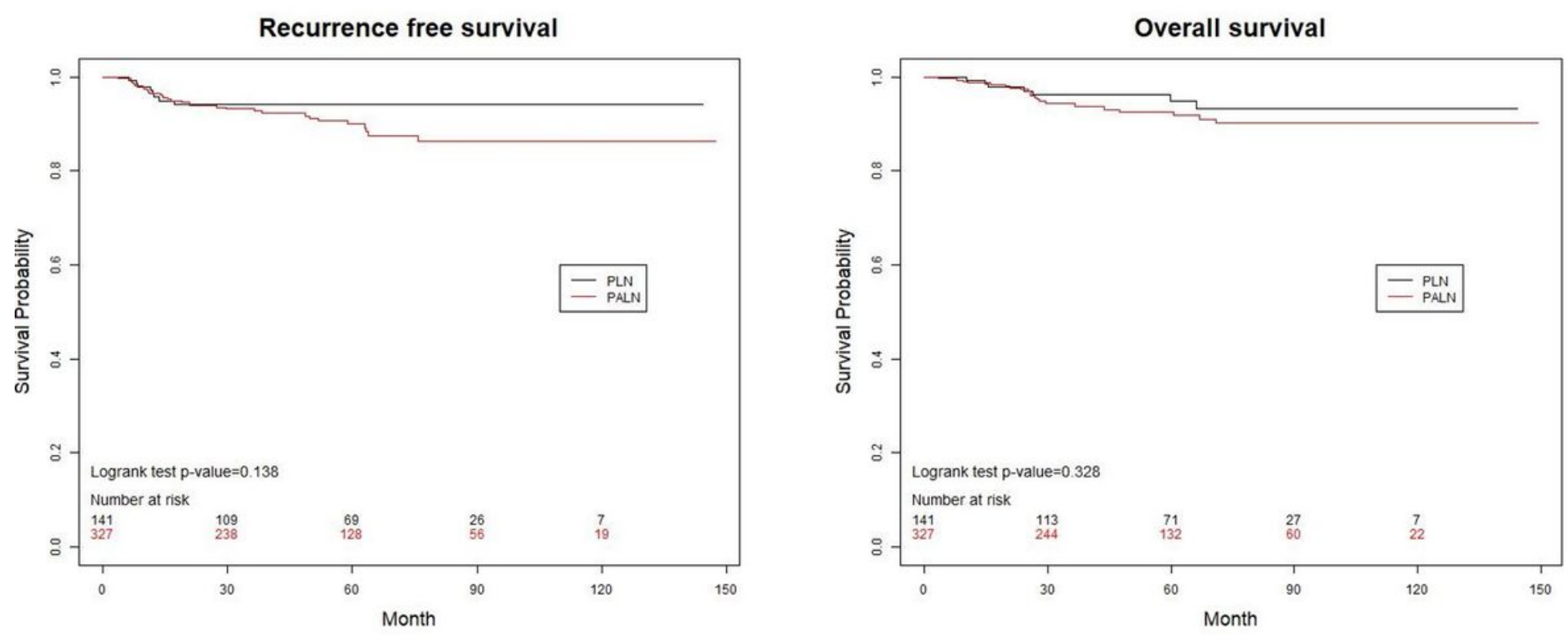

Figure 1. Overall survival and recurrence-free survival rates between pelvic lymphadenectomy and pelvic and paraaortic lymphadenectomy

\section{Figure 1}

Overall survival and recurrence-free survival rates between pelvic lymphadenectomy and pelvic and paraaortic lymphadenectomy 

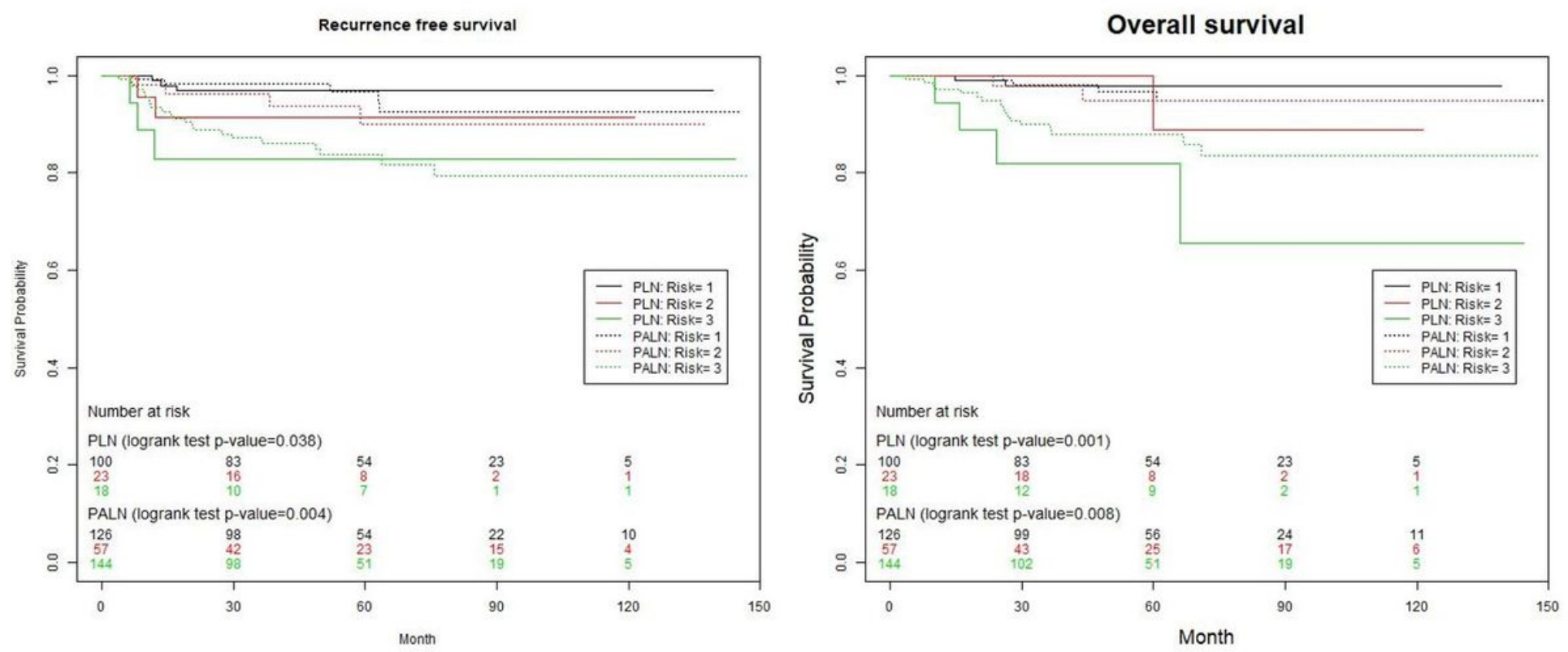

Figure 2. Overall survival and recurrence-free survival rates for sub-categorization by risk groups

\section{Figure 2}

Overall survival and recurrence-free survival rates for sub-categorization by risk groups
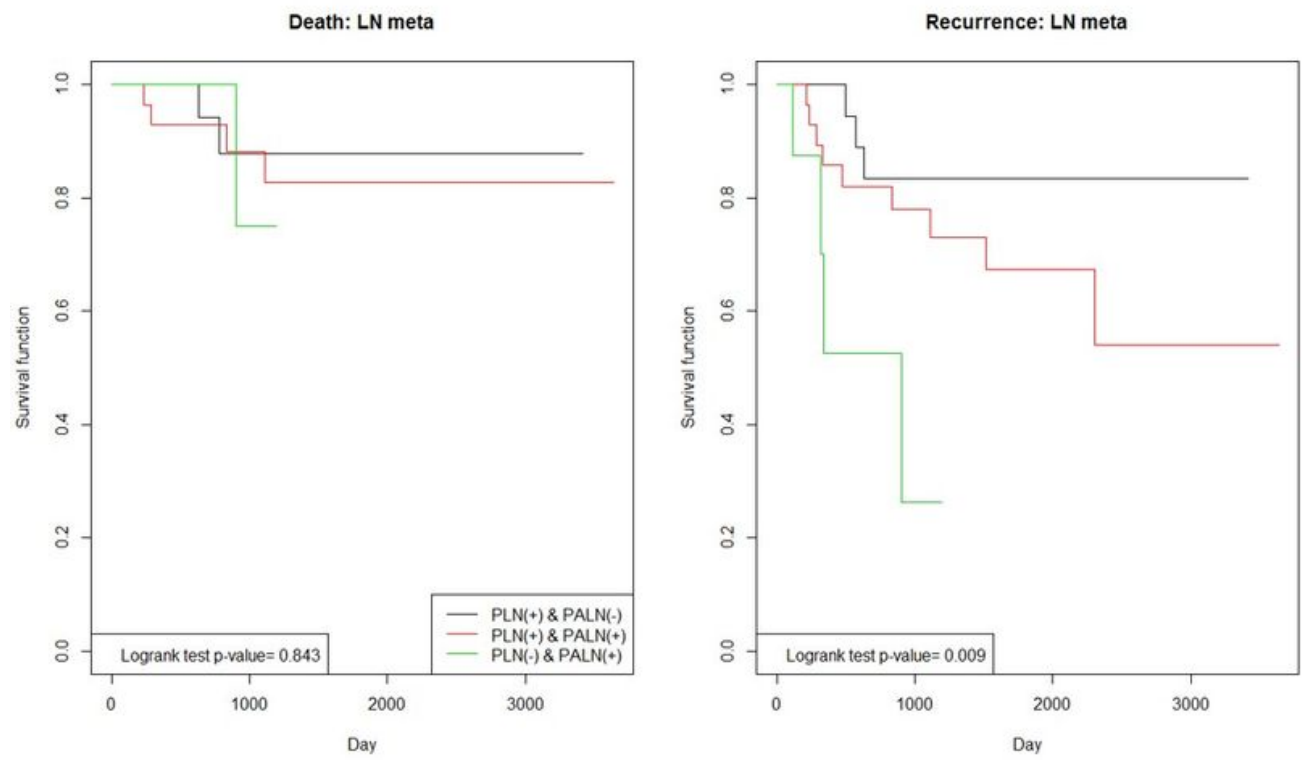

Figure 3. Overall survival and recurrence-free survival rates for sub-categorization by risk groups

\section{Figure 3}

Kaplan-Meier survival curve for sub-categorization of the status of lymph nodal metastatic regions. 